\title{
Pigeonpea genotypes influence parasitization preference and survival and development of the Helicoverpa armigera larval parasitoid, Campoletis chlorideae
}

\author{
Shiddalingappa V Hugar ${ }^{1,2}$, Hari C Sharma ${ }^{* *}$ and Kondikallu Basavan Goud ${ }^{2}$
}

\begin{abstract}
Studies were undertaken to identify pigeonpea, Cajanus cajan (L.) Millspaugh and the wild relative of pigeonpea, Cajanus scarabaeoides (L.) (accession ICPW 125,) genotypes that are hospitable to the pod borer, Helicoverpa armigera (Hübner) (Lepidoptera: Noctuidae) larval parasitoid, Campoletis chlorideae Uchida (Hymenoptera: Ichneumonidae) for the management of this pest in pigeonpea based cropping systems. Percentage parasitization of the $H$. armigera larvae by the $\mathrm{C}$. chlorideae females was greater under no-choice conditions than under multi-choice conditions because of forced parasitization under no-choice conditions. Lowest parasitization was recorded on the wild relative, ICPW 125, which may be due to long nonglandular hairs and low survival of $H$. armigera larvae. Parasitization of $H$. armigera larvae was greater under no-choice, dual-choice and/or multi-choice conditions on ICPL 87, ICPL 87119 and ICPL 87091, which are susceptible to $H$. armigera, than on the pod borer-resistant genotypes ICPL 332WR, ICPL 84060 and ICPB 2042; while survival and development of the parasitoid was better on H. armigera larvae fed on ICPL 87, ICPL 87119, LRG 41, ICP 7035 and ICPL 87091 than on ICPL 332WR, ICPL 84060, ICPB 2042 and ICPW 125. The genotypes ICPL 87, ICPL 87119, LRG 42 and ICPL 87091 that are hospitable to C. chloridae, are better suited for use in integrated pest management to minimize the losses due to $H$. armigera in pigeonpea.
\end{abstract}

Keywords: Pigeonpea; Helicoverpa armigera; Campoletis chlorideae; Biological control; Plant resistance; Tritrophic interactions; Compatibility

\section{Introduction}

Pigeonpea is one of the major pulses grown in the semi-arid tropics between $30^{\circ} \mathrm{N}$ and $30^{\circ} \mathrm{S}$, covering about 50 countries in Asia, Africa and the Americas. It is damaged by more than 200 species of insects, of which Helicoverpa armigera (Hubner) (Lepidoptera: Noctuidae) is the most important pest in the semi-arid tropics (Reed et al. 1989; Sharma 2005). Helicoverpa armigera has a wide host range, and feeds on more than 250 crop species. It has developed very high levels of resistance to conventional insecticides, including synthetic pyrethroids (Kranthi et al. 2002). Helicoverpa armigera is a polyphagous pest (Bilapate 1984; Firempong and Twine 1986), damaging a wide range

\footnotetext{
* Correspondence: H.Sharma@cgiar.com

${ }^{1}$ International Crops Research Institute for the Semi-Arid Tropics, Patancheru 502324, Andhra Pradesh, India

Full list of author information is available at the end of the article
}

of agricultural crops including cotton, tomato, sunflower, grain legumes, vegetables, cereals and fruit crops. It causes an estimated annual loss of over $\$ 350$ million in pigeonpea, and over $\$ 2$ billion in the semiarid tropics on different crops despite application of insecticides costing over $\$ 500$ million annually (Sharma 2005).

Evaluation of more than 14,000 pigeonpea accessions for resistance to $H$. armigera has revealed low to moderate levels of resistance to this pest (Reed and Lateef 1990; Lateef and Pimbert 1990), and several genotypes with moderate levels of resistance to $H$. armigera have been identified (Patnaik et al. 1989; Lateef and Pimbert 1990; Borad et al. 1991; Kalariya et al. 1998). Varieties with moderate levels of resistance to pod borers have also been developed, and/or released for cultivation to the farmers (Sharma et al. 2005, 2010). Genotypes such 
as ICPL 187-1, ICP 7203-1, ICPL 98008, T 21, ICP 7035 and ICPL 332 have shown moderate levels of resistance to $H$. armigera across planting dates (Kumari et al. 2010a). The $H$. armigera larvae reared on leaves or pods of ICPL 332, ICPL 84060, ICP 7035, ICPL 88039 and T 21 exhibit reduced larval and pupal weights, and prolongation of larval and pupal developmental periods, suggesting that antibiosis is one of the mechanisms of resistance, which may have implications for survival and development of the natural enemies of this pest (Kumari et al. 2010b).

Over 250 natural enemies have been recorded on H. armigera (Romeis and Shanower 1996), of which, the egg parasitoids, Trichogramma spp. and the larval parasitoids, Campoletis chlorideae Uchida (Hymenoptera: Ichneumonidae), Carcelia illota Curran, Palexotista spp., and Goniozus spp. are predominant parasitoids of $H$. armigera in different agro-ecosystems. However, the activity and abundance of natural enemies varies across crops (Pawar et al. 1986), and different genotypes of the same crop (Romeis and Shanower 1996; Sharma et al. 2003; Dhillon and Sharma 2007). Host plant selection by the female parasitoids, involves a series of complex responses in a non-random manner to a hierarchy of physical and/or chemical stimuli that lead them to their potential hosts (Vet and Groenewold 1990; Lewis et al. 1991; Tumlinson et al. 1993). Parasitoids also respond to the volatiles emanating from both undamaged (McAuslane et al. 1990; Li et al. 1992; Turlings and Tumlinson 1992; Udayagiri and Jones 1992) and damaged (Whitman 1988; Turlings et al. 1990, 1995; Mattiaci et al. 1994; de Moraes et al. 1998; War et al. 2011) plants.

Genotypic resistance has a considerable influence on parasitism of insect pests in different crops. The nature of influence depends on the insect pest, natural enemy, and the crop (Sharma et al. 2003). The rates of parasitism by Campoletis sonorensis (Cameron) and Cotesia congregata (Say) have been reported to be significantly lower on the resistant wild tomato, Lycopersicon hirsutum f. glabratum (accession PI 134417), but had little effect on parasitism by Cotesia marginiventris (Cresson) and Cardiochiles nigriceps Viereck (Farrar et al. 1994). In chickpea, parasitism of $H$. armigera larvae by $C$. chlorideae ranged from 8.33 to $28.00 \%$ (Gupta and Raj 2003), and varied considerably across genotypes (Kaur et al. (2004). However, there is no information on genotypic effects on the activity and abundance of natural enemies in pigeonpea. The present studies were undertaken to study the effect of different genotypes of pigeonpea on the parasitization of $H$. armigera larvae by $C$. chlorideae to identify genotypes that are compatible with the natural enemies of this pest.

\section{Material and methods \\ Experimental material \\ Plant material}

Eight pigeonpea genotypes (ICPL 87, ICPL 87119, and ICPL 87091-susceptible, LRG 41, T 21, and ICP 7035-moderately resistant, and ICPL 84060, ICPL $332 \mathrm{WR}$ and ICPB 2042 (Hairy pods) - resistant) and one accession of wild relative of pigeonpea, Cajanus scarabaeoides (L.) (ICPW 125) were grown in the field during the rainy season (June-Dec) in deep black soils (Vertisols). The test genotypes were planted twice at 30 day intervals to produce flowers and pods of all genotypes at the same time. Normal agronomic practices, as per ICRISAT procedure, were followed for raising the crop, but without insecticide application. The inflorescences were covered with a nylon bag at the initiation of flowering (flower bud formation) to protect the test samples from natural infestation by the insects.

\section{Maintenance of insect cultures \\ Pod borer, H. armigera}

The $H$. armigera culture was initiated by collecting the larvae from the farmers' fields and reared on the natural host for one generation before being introduced into the laboratory culture to avoid contamination with the nuclear polyhedrosis virus, bacteria or fungi. The $H$. armigera was reared on a chickpea flour based semi-synthetic artificial diet (Armes et al. 1992).

\section{Larval parasitoid, C. chlorideae}

The cocoons of $C$. chlorideae were collected from chickpea fields and kept individually in a glass vial ( $2 \mathrm{~cm}$ in diameter, and $10 \mathrm{~cm}$ in length) and plugged with cotton wool. Twenty newly eclosed female adult wasps were kept in each cage $(10 \mathrm{~cm}$ diameter $\times 20 \mathrm{~cm}$ length, and covered with a lid having 60 wire-mesh) with other virgin wasps. A cotton swab with $10 \%$ sucrose solution was placed inside the cage as a food for the parasitoid adults. After mating, the females were used for parasitization of second instar $H$. armigera larvae, and then reared on chickpea based artificial diet as described by Sharma et al. (2008). The culture was maintained at $27 \pm 2^{\circ} \mathrm{C}, 65-75 \% \mathrm{RH}$, and $12 \mathrm{~h}$ photoperiod. Mated females and progeny of the same parent (originating from isofemales, i.e. culture initiated from a single female) were used for the experiments.

\section{Effectiveness of $C$. chlorideae in parasitization of $H$. armigera larvae on different genotypes of pigeonpea}

The effect of different genotypes of pigeonpea on parasitization of $H$. armigera larvae by the females of $C$. chorideae was studied under no-choice, dual-choice, and multi-choice conditions. For this purpose, the inflorescences (30 cm long) of different genotypes at the initiation of podding (with $50 \%$ flowers) were cut with a sharp knife, 


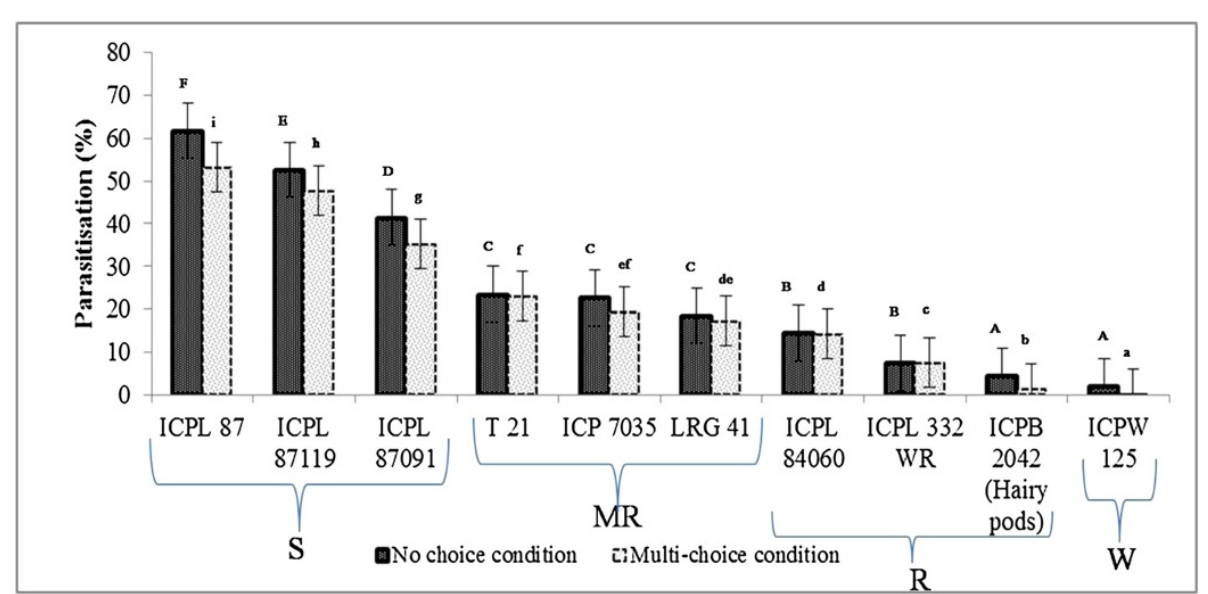

Figure 1 Influence of different pigeonpea genotypes on parasitization of $H$. armigera larvae by $C$. chlorideae females under no-choice and multi-choice conditions. The bars followed by the same letter (upper or lower case) are not statistically significant at P $\leq 0.05$. S-Susceptible, MR-Moderately resistant, R-Resistant, and W-Wild resistant.

and immediately placed in a $100 \mathrm{ml}$ conical flask containing $75 \mathrm{ml}$ of one per cent sucrose solution, and held in an upright position using cotton wool. The inflorescences were infested with the 30 laboratory-reared second-instar $H$. armigera larvae. After $6 \mathrm{~h}$, the infested inflorescences were exposed to the three, six and ten pairs of $C$. chlorideae females under no-choice, double-choice and multi-choice conditions, respectively inside a cage $(30 \times 30 \times 30 \mathrm{~cm})$. The wasps were provided with $10 \%$ sucrose solution on a cotton swab as a food. After $48 \mathrm{~h}$, the larvae were collected from the infested inflorescences and placed individually in $15 \mathrm{ml}$ glass vials containing $10 \mathrm{~g}$ artificial diet. The larvae were reared on the artificial diet until cocoon formation.

\section{No-choice conditions}

Under no-choice conditions, a single inflorescence of the test genotype was kept inside a wooden cage $(30 \times 30 \times 30 \mathrm{~cm})$. Each experiment was repeated twice, and each set replicated 10 times.

\section{Dual-choice conditions}

Under dual-choice conditions, the C. chlorideae females were offered the choice between the infested inflorescence of the test genotype and of the susceptible check, ICPL 87 placed at the opposite ends of a wooden cage. $(30 \times 30 \times 30 \mathrm{~cm})$. Each experiment was repeated 10 times. After $48 \mathrm{~h}$, the relative parasitization (\%) preference was computed as follows.
No effect on parasitization $=$ No difference in relative parasitization between the test genotype and the susceptible check, ICPL 87.

Negative effect on parasitization $=$ Parasitization of the $H$. armigera larvae on the test genotype is significantly lower than on the susceptible check, ICPL 87.

Positive effect on parasitization $=$ Parasitization of $H$. armigera larvae on the test genotype is significantly greater than on the susceptible check, ICPL 87.

\section{Multi-choice conditions}

Under multi-choice conditions, the inflorescences of all the 10 test genotypes were arranged in a circular arena inside a wooden cage $(60 \times 60 \times 60 \mathrm{~cm})$. The experiment was conducted in a completely randomized block design, with two sets having three replications in each set. Observations were recorded on the numbers of $H$. armigera larvae recovered, and the proportion of larvae parasitized by $C$. chlorideae. For recording the numbers of $H$. armigera larvae parasitized by $C$. chlorideae, the larvae collected from inflorescences of one set were dissected immediately by placing them in a drop of Ringer's solution on a glass slide under a stereomicroscope, and the percentage parasitization was calculated as follows (Tian et al. 2008).

\footnotetext{
Percentage parasitization $=[($ Number of larvae parasitized $) /$ (Number of larvae effectively parasitzed + number of healthy larvae) $\times 100$.
}

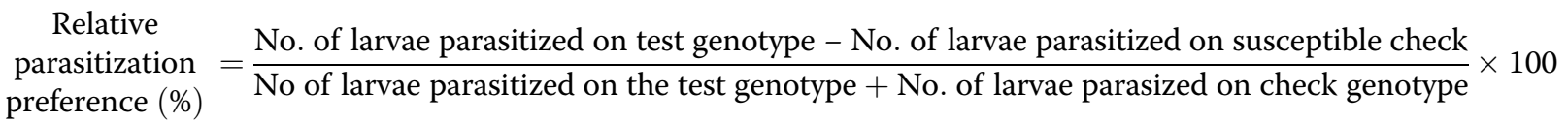


The second set was used to record the survival and development of C. chlorideae as follows;

$$
\begin{aligned}
\text { Cocoon formation }(\%)= & (\text { Number of cocoons formed } / \\
& \text { Number of larvae parasitized }) \times 100 .
\end{aligned}
$$

Adult emergence $(\%)=($ Number of adults emerged $/$

$$
\text { Number of cocoons formed) } \times 100 \text {. }
$$

Data were also recorded on egg and larval period, pupal period, and sex ratio of the parasitoid.

\section{Statistical analysis}

The data from no-choice, dual-choice and multiple choice conditions were subjected to analysis of variance using Genstat 13th edition. Significance of differences between the genotypes under no-choice and multi-choice conditions was tested by F-test, while the significance of differences between the genotypic means was judged by least significant difference at $\mathrm{P}=0.05$. Under dual-choice conditions, the significance of differences between the test genotypes and the susceptible check was judged by the students' paired t-test at $\mathrm{P}=0.05$.

\section{Results}

Effectiveness of $C$. chlorideae in parasitization of $H$. armigera larvae on different genotypes of pigonpea No-choice conditions

Under no-choice cage conditions, there were significant differences in larval parasitization on different pigeonpea genotypes, and highest parasitization was recorded on ICPL 87 (61.74\%), followed by ICPL 87119 (52.55\%), ICPL 87091 and (41.39\%) (Figure 1). Larval parasitization was quite low $(4.50-23.41 \%)$ on $\mathrm{T} 21$, ICP 7035, LRG 41, ICPL 84060, ICPL 332WR, and
ICPB 2042, suggesting that these genotypes were not hospitable to the larval parasitoid, C. chlorideae. Least larval parasitization was observed on the pigeonpea wild relative, C. scarabaeoides accession ICPW 125 $(2.00 \%)$, probably because of the presence of long hairs and/or chemicals that may be repellent to the adult wasps, and the possible adverse effects of secondary metabolites in this accession on the parasitoid survival and development.

\section{Dual-choice conditions}

Under dual-choice conditions, when the parasitoid females were offered a choice between the test cultivar and the susceptible check, ICPL 87, greater parasitization was recorded in the larvae released on ICPL 87 than on the test cultivars. The differences were much larger in case of ICPL 84060 (18.39 vs 53.82\%), T 21 (21.14 vs 51.94\%), ICPL 332 WR (11.43 vs 47.20\%) and ICPW 125 (2.08vs $24.62 \%$ ) (Figure 2). The relative parasitization preference in relation to the susceptible check, ICPL 87 (RPP) by $C$. chlorideae on different test genotypes as compared to ICPL 87 ranged from -5.01 to $-84.2 \%$. Highest RPP of $-84.2 \%$ was observed on ICPW 125 , followed by ICPL 332WR (-61.01\%), ICPB 2042 (-58.96\%), ICPL $84060(-49.07 \%)$ and T $21(-42.14 \%)$ (Figure 3).

\section{Multi-choice conditions}

Under multi-choice conditions, percentage larval parasitization was highest on the susceptible check, ICPL 87 (53.33\%), followed by ICPL 87119 (47.67\%). Least parasitization was recorded on C. scarabaeoides accession, ICPW 125 (0.13\%), followed by ICPB 2042 (1.32\%). The percentage parasitization of $H$. armigera larvae on rest of the genotypes varied from 7.46 to $35.33 \%$ (Figure 1 ).

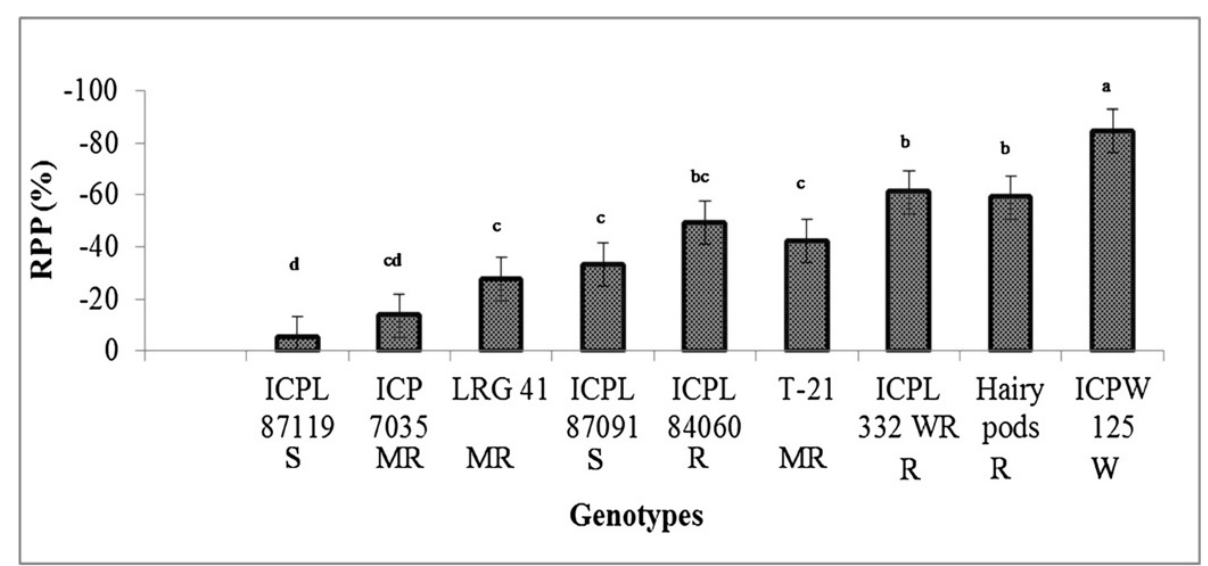

Figure 2 Parasitization of $2^{\text {nd }}$ instar larvae of $H$. armigera by $C$. chlorideae females on different genotypes of pigeonpea under dual-choice conditions. The bars followed by the same letter are not statistically significant at $P \leq 0.05$. RPP = Relative parasitization preference in relation to the susceptible check, ICPL 87. S-Susceptible, MR-Moderately resistant, R-Resistant, and W-Wild resistant. 


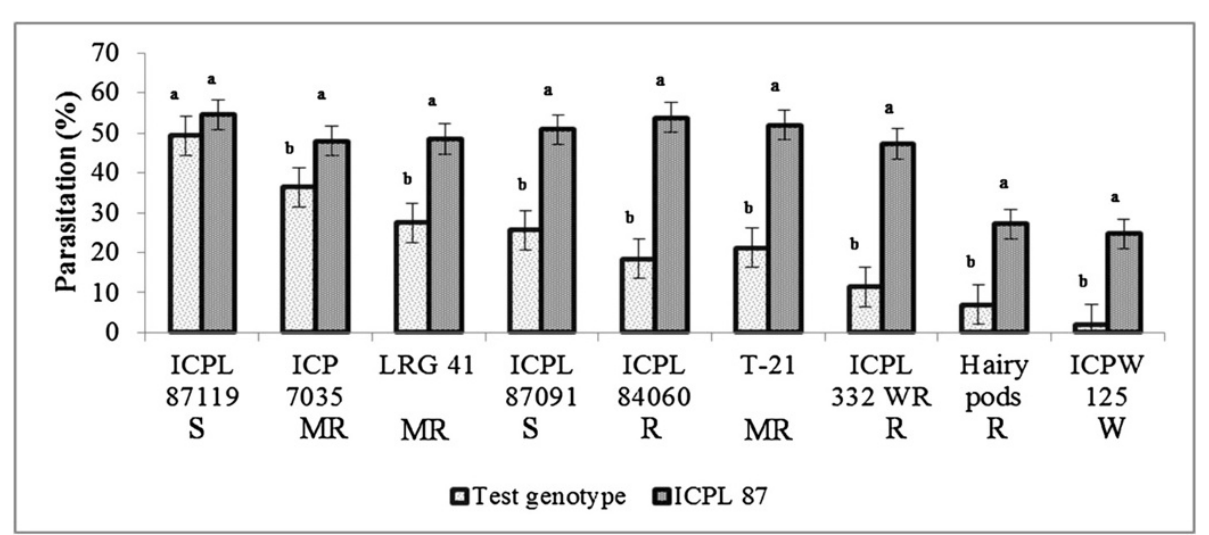

Figure 3 Parasitization preference of $C$. chlorideae females towards $2^{\text {nd }}$ instar larvae of $H$. armigera on different genotypes of pigeonpea in relation to the susceptible check, ICPL $\mathbf{8 7}$ under dual-choice conditions. A pair of bars followed by the same letter are not statistically significant at $\mathrm{P} \leq 0.05$. S-Susceptible, MR-Moderately resistant, R-Resistant, and W-Wild resistant.

Effect of different pigeonpea genotypes on the development and survival of C. chlorideae

Egg + larval period of $C$. chlorideae reared on $H$. armigera larvae fed on the susceptible check, ICPL 87 was shortest (7.33 days), followed by those fed on ICPL 87119 (8.33 days). The egg + larval developmental period of $C$. chlorideae was prolonged when the $H$. armigera larvae were reared on ICP 7035 (11.00 days), ICPB 2042 (12.00 days), ICPL 332 WR (12.33 days) and ICPW 125 (16.00 days) (Table 1). The pupal period of C. chlorideae was shorter when the $H$. armigera larvae were fed on ICPL 87119 (7.68 days), followed T 21 (8.07 days), ICPL 87 (8.21 days) and ICPL 87091 (8.64 days) as compared to those fed on ICPL 332WR (9.40 days), ICP 7035 (9.57 days), ICPL 84060 (9.83 days) and LRG 41 (9.87 days). Pupal period of $C$. chlorideae was prolonged by 4-6 days when the $H$. armigera larvae were reared on the flowers/pods of ICPB 2042 and ICPW 125 (Table 1).

Percentage cocoon formation of $C$. chlorideae was greater when the $H$. armigera larvae were fed on ICP 7035 (33.57\%), followed by the larvae fed on ICPL 87119 (31.81\%). Cocoon formation ranged from 19.91-22.03\% when the $H$. armigera larvae were reared on ICPL 87, T 21, ICPL 84060, ICPL 87091 and LRG 41. However, cocoon formation was significantly lower (9.00-14.70\%) when the $H$. armigera larvae were fed on ICPB 2042, ICPL 332WR and ICPW 125 as compared to that on ICPL 87119 (Table 1). Adult emergence of $C$. chlorideae was highest when the $H$. armigera larvae were reared on flowers/pods of ICP 7035 (40.33\%), followed by LRG 41 (39.67\%). Least adult emergence was recorded on ICPW 125 (3.33\%), followed by ICPB 2042 (5.33\%). Longevity of $C$. chlorideae adults was maximum when reared on

Table 1 Development and survival of Campoletis chlorideae parasitizing $2^{\text {nd }}$ instar $\boldsymbol{H}$. armigera larvae on different genotypes of pigeonpea (ICRISAT, Patancheru, 2009-2010)

\begin{tabular}{|c|c|c|c|c|c|}
\hline Genotypes & $\begin{array}{c}\text { Egg + larval } \\
\text { period (days) }\end{array}$ & Pupal period (days) & Cocoon formation (\%) & Adult emergence (\%) & Adult longevity (days) \\
\hline ICPL $87 \mathrm{~S}$ & $7.33 \pm 0.33^{\mathrm{a}}$ & $8.21 \pm 0.15^{\mathrm{ab}}$ & $22.03 \pm 0.60(27.98 \pm 0.62)^{b}$ & $17.00 \pm 1.15(24.32 \pm 1.17)^{d}$ & $23.00 \pm 3.06^{c}$ \\
\hline ICP 7035 MR & $11.00 \pm 0.58^{d}$ & $9.57 \pm 0.43^{c}$ & $33.57 \pm 1.83(35.39 \pm 1.94)^{a}$ & $40.33 \pm 4.06(39.38 \pm 4.43)^{a}$ & $29.00 \pm 1.15^{d}$ \\
\hline LRG $41 \mathbf{M R}$ & $9.33 \pm 0.34^{b c}$ & $9.87 \pm 0.13^{c}$ & $19.91 \pm 1.42(26.47 \pm 1.45)^{b}$ & $39.67 \pm 0.87(39.03 \pm 0.96)^{a}$ & $20.00 \pm 3.46^{b c}$ \\
\hline ICPL 87091 S & $9.33 \pm 0.32^{b c}$ & $8.64 \pm 0.18^{\mathrm{abc}}$ & $20.25 \pm 0.64(26.74 \pm 0.65)^{b}$ & $24.00 \pm 2.08(29.29 \pm 2.15)^{c}$ & $29.70 \pm 0.88^{d}$ \\
\hline ICPL 84060 R & $9.00 \pm 0.10^{b c}$ & $9.83 \pm 0.17^{c}$ & $19.93 \pm 0.93(26.50 \pm 0.95)^{b}$ & $33.00 \pm 0.56(35.05 \pm 0.61)^{b}$ & $18.70 \pm 0.33^{b c}$ \\
\hline T $21 \mathbf{M R}$ & $9.73 \pm 0.18^{c}$ & $8.07 \pm 0.30^{\mathrm{a}}$ & $20.14 \pm 0.71(26.67 \pm 0.72)^{b}$ & $15.67 \pm 1.20(23.28 \pm 1.22)^{d}$ & $19.00 \pm 0.58^{b c}$ \\
\hline ICPL 332 WR R & $12.33 \pm 0.88^{e}$ & $9.4 \pm 0.87^{b c}$ & $14.28 \pm 0.62(22.19 \pm 0.63)^{c}$ & $9.67 \pm 1.10(18.05 \pm 1.20)^{e}$ & $18.00 \pm 0.58^{b c}$ \\
\hline ICPB 2042 (Hairy pods) $\mathbf{R}$ & $12.00 \pm 0.57^{\mathrm{de}}$ & $12.17 \pm 0.17^{d}$ & $14.70 \pm 1.32(22.50 \pm 1.33)^{c}$ & $5.33 \pm 0.86(13.26 \pm 0.87)^{f}$ & $14.33 \pm 1.76^{\mathrm{ab}}$ \\
\hline ICPW 125 W & $16.00 \pm 0.56^{f}$ & $14.48 \pm 0.37^{e}$ & $9.00 \pm 0.58(17.44 \pm 0.57)^{d}$ & $3.33 \pm 0.87(10.34 \pm 0.86)^{f}$ & $10.70 \pm 0.88^{\mathrm{a}}$ \\
\hline SE \pm & 0.425 & 0.404 & 0.74 & 1.20 & 1.718 \\
\hline $\operatorname{LSD}\left(\mathrm{P}_{0.05}\right)$ & $1.264^{*}$ & $1.202^{*}$ & $2.98^{*}$ & $4.83^{*}$ & $5.11^{*}$ \\
\hline
\end{tabular}

Values in parentheses are Arcsine transformed. The values followed by the same letter within a column are statistically non-significant at $\mathrm{P} \leq 0.05$. S-Susceptible, MR-Moderately resistant, R-Resistant, and W-Wild resistant. 
H. armigera larvae fed on ICPL 87091 (29.70 days), followed by ICP 7035 (29.00 days). The adult longevity was significantly lower in $C$. chlorideae reared on $H$. armigera larvae fed on ICPW 125 (10.70 days) and ICPB 2042 (14.33 days) than those fed on ICP 7035 and ICPL 87091.

\section{Discussion}

Effectiveness of natural enemies for controlling insect pests varies across crops, and different genotypes of the same crop (Sharma 1993; Sharma et al. 2003; Kaur et al. 2004; Dhillon and Sharma 2007). The present studies showed that the parasitization efficiency of the $H$. armigera larval parasitoid, C. chlorideae varies across different genotypes of pigeonpea. The host genotype not only influenced the parasitization of the host larvae, but also the survival and development of $C$. chlorideae, which may be because of the effect of the morphological and biochemical characteristics of the host genotype on $H$. armigera larvae, and the indirect effects on C. chlorideae. Percentage parasitization was greater under no-choice conditions as compared to that under multi-choice conditions, which may be largely because of non-availability of alternate host plant to the females of $C$. chlorideae. When the parasitoids were given a choice of all the test genotypes under multi-choice conditions, greater numbers of parasitoids were involved in seeking the host larvae, resulting in intraspecific competition, which might have resulted in lower levels of parasitism under multi-choice conditions. Competition is one of several factors influencing the effectiveness of parasitoids (Sirot and Bernstein 1996).

The $H$. armigera larvae feeding on susceptible genotypes, ICPL 87 and ICPL 97119 suffered significantly greater parasitization by $C$. chlorideae than the other genotypes tested under no-choice, dual-choice and multi-choice conditions, suggesting that host genotype plays a significant role in the effectiveness of $C$. chlorideae in pasitization of $H$. armigera larvae. Kaur et al. (2004) reported that as the incidence of a pest increases, the parasitoid activity also increases. In the present studies, the increased parasitization of $H$. armigera on the susceptible genotypes may also be influenced by survival of more numbers of $H$. armigera larvae on the susceptible genotype and lack of resistance to the herbivore, and possibly production of greater amounts of the volatile compounds that attract the $C$. chlorideae females for parasitization (War et al. 2011).

Clustering type of podding habit of ICPL 87 possibly provided more surface area for the movement of the $H$. armigera larvae, rendering them more prone to parasitization by C. chlorideae. ICPL 87119 - which has thicker pod walls, possibly hindered the entry of the $H$. armigera larvae into the pods making them more prone to parasitization by $C$. chlorideae. Creeping type growth habit and thick plant canopy of the C. scarabaeoides accession, ICPW 125 recorded lowest parasitization under no-choice, dual-choice and mulit-choice conditions, which may be due to the presence of long nonglandular hairs and low survival of $H$. armigera larvae because of high levels of resistance to $H$. armigera (Aruna et al. 2005; Sujana et al. 2008; Sharma et al. 2009), and a different blend of the chemicals on the pod surface (Green et al. 2002) and/or volatile compounds (Sharma et al. 2001) which influence the survival and development of the insect host, $H$. armigera. Behavior and parasitism rates of Trichogramma pretiosum (Riley) and Trichogramma minutum (Riley) in $H$. armigera are influenced by trichome and gossypol containing glands in cotton (El-Wakeil 2011), while $t$ richomes in pigeonpea inhibit the searching behavior of T. chilonis Ishii (Romeis et al. 1998).

Pigeonpea genotypes also showed substantial effects on the survival and development of $C$. chlorideae parasitizing second-instar $H$. armigera larvae. Egg + larval period and pupal period were longest on the C. scarabaeoides accession, ICPW 125 and shortest postembryonic developmental period was recorded on the $H$. armigera susceptible genotype ICPL 87 , suggesting that secondary metabolites ingested by the $H$. armigera larvae from the host genotype either directly affected the survival and development of the parasitoid, C. chlorideae or through suboptimal prey because of poor growth of the $H$. armigera larvae due the adverse effects of the secondary metabolites, and/or poor nutritional quality of the insect and plant host. Changes in biochemical composition of host plants in response to herbivory also influence the growth and survival of herbivores (Gange and Brown 1989; Whitaman et al. 1991), which in turn influences the activity and abundance of natural enemies (Bloem and Duffey 1990). Sithanantham et al. (1982) observed that parasitism of $H$. armigera larvae in chickpea was lower on the resistant genotypes than on the susceptible ones. The results of the present studies suggested that the ICPW 125, ICPB 2042 and ICPL 332WR are not compatible with the H. armigera larval parasitoid C. chlorideae.

Parasitization of $H$. armigera larvae by $C$. chlorideae was greater under no-choice, dual-choice and/or multi-choice conditions on ICPL 87, ICPL 87119 and ICPL 87091, which are susceptible to $H$. armigera than on the resistant genotypes ICPL 332WR, ICPL 84060, LRG 41 (Kumari et al. 2010a). Survival, development of the parasitoid was better on ICPL 87119, LRG 41, ICP 7035 and ICPL 87091 than on ICPL 332WR, ICPL 84060, ICPB 2042 and ICPW 125 - the pod borer resistant genotypes. The genotypes ICPL 87, ICPL 87119, LRG 42 and ICPL 87091, that are hospitable to C. chloridae, are more suitable for use in integrated pest management to minimize the damage by $H$. armigera in pigeonpea. These varieties have also been released for cultivation to the farmers and have acceptable grain quality, except ICPL 
87091. In view of the variation observed in genotypic resistance to $H$. armigera, there is need for in-depth studies to assess the genotypic compatibility with the natural enemies of the crop pests for integrated pest management.

The larvae of $H$. armigera, which escape parasitization continue to develop and produce the next generation. The surviving population becomes the source for future generations of the parasitoids, which develop in the parasitized larvae and contribute to the natural balance between the pest and the natural enemies. The continuous and cumulative effect of the natural enemies on insect pests reduces the overdependence on synthetic pesticides for pest management, and thus, contributes to environment conservation. The genotypes that are compatible with the natural enemies may also be used by the organic farming community for producing food free from pesticides.

\section{Competing interest}

The authors declare that they have no competing interests.

\section{Authors' contributions}

SVH carried out the research work on the "Pigeonpea Genotypes Influence Parasitization efficiency and survival and development of the Helicoverpa armigera Larval Parasitoid, Campoletis chlorideae". Rearing and maintenance of the $\mathrm{H}$. armigera and $\mathrm{C}$. chlorideae culture for conducting the experiments. Growing of different pigeonpea genotypes under ideal conditions and unbiased under the greenhouse condition and the inflorescence were covered with the nylon net to avoid the field infestation of the insect pest. Constructed the cages and conducted the experiment to study Effectiveness of $\mathrm{C}$. chlorideae in parasitization of $\mathrm{H}$. armigera larvae on different genotypes of pigeonpea under no-choice, dual-choice and multi-choice condition.

Conducted the experiment on the development and survival of C. chlorideae on different pigeonpea genotypes. Statistical analysed the data for interpretation of the findings. HCS Provided plant materials, laboratory, materials, labors etc for conducting the experiments. Given scientific guidelines, way of conducted the experiments and guidance for conducting the experiments. Drafted the manuscripts for publication in the Journal. KBG Given procedure for conducting the experiments and drafted the manuscripts and statistically analysed data for publication in the Journal. All authors read and approved the final manuscript.

\section{Acknowledgements}

We thank the staff of entomology, ICRISAT for help in insect rearing and bioassays. We also thank Dr AR War for critical review of the manuscript, and the National Food Security Mission, Ministry of Agriculture and Cooperation, Government of India, for financial support for this work.

\section{Author details}

${ }^{1}$ International Crops Research Institute for the Semi-Arid Tropics, Patancheru 502324, Andhra Pradesh, India. ²Department of Agricultural Entomology, College of Agriculture, University of Agricultural Sciences (UAS), Dharwad 580005, Karnataka, India.

Received: 21 April 2014 Accepted: 22 July 2014

Published: 28 July 2014

\section{References}

Armes NJ, Bond GS, Cooter RJ (1992) The laboratory culture and development of Helicoverpa armigera. Natural Resources Institute Bulletin, 57, Chatham, UK

Aruna R, Manohar Rao D, Reddy L, Upadhyaya HD, Sharma HC (2005) Inheritance of trichomes and resistance to pod borer (Helicoverpa armigera) and their association in interspecific crosses between cultivated pigeonpea (Cajanus cajan) and its wild relative C. scarabaeoides. Euphytica 145:247-257 Bilapate GG (1984) Heliothis complex in India: a review. Agric Rev London 5:13-26
Bloem KA, Duffey SS (1990) Effect of protein type and quantity on growth and development of larval Heliothis zea and Spodoptera exigua and the endoparasitoid Hyposter exigua. Entomol Exp Applic 54:141-148

Borad PK, Patel JR, Patel MG (1991) Evaluation of vegetable pigeonpea (Cajanus cajan) genotypes resistant to gram-pod borer (Helicoverpa armigera), plume moth (Marasmarcha liophanes) and podfly (Melanagromyza obtusa). Indian $J$ Agric Sci 61:682-684

De Moraes CM, Lewis WJ, Pare PW, Alborn HT, Tumlinson JH (1998) Herbivore infested plants selectively attract parasitoids. Nature 393:570-573

Dhillon MK, Sharma HC (2007) Survival and development of Campoletis chlorideae on various insect and crop hosts: implications for Bt-transgenic crops. J Appl Entomol 131(3):179-185

El-Wakeil NE (2011) Impacts of cotton traits on the parasitization of Heliocoverpa armigera eggs by Trichogramma species. Gesunde Pflanzen 63:83-93

Farrar RR Jr, Barbour JD, Kennedy GG (1994) Field evaluation of insect resistance in a wild tomato and its effects on insect parasitoids. Entomol Exp Applic 71:211-226

Firempong S, Twine P (1986) The biology and ecology of $H$. armigera and $H$. punctigera (Wallengren) (Lepidoptera: Noctuidae) in Australia: what do we know? Aust J Zool 34:779-814

Gange AC, Brown VK (1989) Effects of root herbivory by an insect on a foliar-feeding species, mediated through changes in the host plant. Oecologia 81:38-42

Green PWC, Stevenson PC, Simmonds MSJ, Sharma HC (2002) Can larvae of the pod borer, Helicoverpa armigera (Noctuidae: Lepidoptera), select between wild and cultivated pigeonpea, Cajanus sp. (Fabaceae)? Bull Ent Res 92:45-51

Gupta RK, Raj D (2003) Natural parasitism by Campoletis chlorideae Uchida, a promising parasitoid of Helicoverpa armigera (Hubner) on chickpea. J Biol Control 17:9-12

Kalariya GB, Judal GS, Patel GM (1998) Reaction of pigeonpea genotypes against important insect pests. Gujarat Agric Uni Res J 23:33-38

Kaur S, Brar KS, Shehnmar M (2004) Effect of different chickpea cultivar on parasitization of Helicoverpa armigera (Hubner) by Campoletis chlorideae Uchida. J Biol Control 18:69-72

Kranthi KR, Jadhav DR, Kranthi S, Wanjari RR, Ali SS, Russel DA (2002) Insecticide resistance in five major insect pests of cotton in India. Crop Prot 21:449-460

Kumari AD, Reddy DJ, Sharma HC (2010a) Stability of resistance to pod borer, Helicoverpa armigera in pigeonpea. Indian J Plant Prot 38(1):6-12

Kumari AD, Sharma HC, Reddy JD (2010b) Incorporation of lyophilized leaves and pods into artificial diet to assess antibiosis component of resistance to pod borer in pigeonpea. J Fd Leg 23:57-65

Lateef SS, Pimbert MP (1990) The search for host plant resistance of Helicoverpa armigera in chickpea and pigeonpea at ICRISAT Pages 14-18. In: Proceedings of the Consultative Group Meeting on the host selection behavior of Helicoverpa armigera, 5-7 March 1990. International Crops Research Institute for the Semi-Arid Tropics, Patancheru 502 324, Andhra Pradesh, India

Lewis WJ, Tumlinson JH, Krasnoff S (1991) Chemically mediated associative learning: an important function in the foraging behavior of Microplitis croceipes (Cresson). J Chem Ecol 17:1309-1325

Li Y, Dickens JC, Steiner WWM (1992) Antennal olfactory responsiveness of Microplitis croceipes (Hymenoptera: Braconidae) to cotton plant volatiles. J Chem Ecol 18:1761-1773

Mattiaci L, Dicke M, Posthumus MA (1994) Induction of parasitoid attracting synomone in Brussels sprouts plant by feeding of Pieris brassicae larva: role of mechanical damage and herbivore elicitor. J Chem Ecol 20:2229-2247

McAuslane HJ, Vinson SB, Williams HJ (1990) Influence of host plant on mate location by parasitoid Campoletis sonorensis (Hymenoptera:Ichneumonidae). Environ Entomol 19:26-31

Patnaik NC, Dash AN, Mishra BK (1989) Effect of intercropping on the incidence of pigeonpea pests in Orissa, India. Int Pigeonpea Newslett 9:24-25

Pawar CS, Bhatnagar VS, Jadhav DR (1986) Heliothis species and their natural enemies, with their potential for biological control. Proc Indian Acad Sc (Anim Sci) 95(6):695-703

Reed W, Lateef SS (1990) Pigeonpea: pest management. In: Nene YL, Hall SD, Sheila VK (eds) The pigeonpea. CAB International, Wallingford, UK, pp 349-374

Reed W, Lateef SS, Sithanantham S, Pawar CS (1989) Pigeonpea and chickpea insect identification handbook. In: International Crops Research Institute for the Semi Arid Tropics. Information Bulletin No: 26, Patancheru, A.P. India, p 120

Romeis J, Shanower TG (1996) Arthropod natural enemies of Helicoverpa armigera (Hubner) (Lepidoptera: Noctuidae) in India. Biocont Sci and Techn 6:481-508

Romeis J, Shanower TG, Zebitz CPW (1998) Physical and chemical plant characters inhibiting the searching behaviour of Trichogramma chilonis. Entomol Exp Applic 87:275-284 
Sharma HC (1993) Effect of insecticide application and host plant resistance on parasitization of sorghum midge, Contarinia sorghicola. Biocont Sc Technol 4:53-60

Sharma HC (ed) (2005) Heliothis/Helicoverpa management: emerging trends and strategies for future research. Oxford \& IBH, and Science Publishers, USA, New Delhi, India, p 469

Sharma HC, Green PWC, Stevenson PC, Simmonds SMJ (2001) What makes it so tasty for the pest? Identification of Helicoverpa armigera feeding stimulants and the location of their production in pigeonpea, Final technical report submitted to Department for International Development, United Kingdom. ICRISAT, Patancheru 502 324, Andhra Pradesh, India, p 85

Sharma HC, Pampapathy G, Sullivan DJ (2003) Influence of host plant resistance on activity and abundance of natural enemies. In: Ignacimuthu S, Jayaraj S (eds) Biological control of insect pests. Phoenix Publishing House, New Delhi, India, pp 282-296

Sharma HC, Pampapathy G, Dhillon MK, Ridsdill S (2005) Detached leaf assay to screen for host plant resistance to Helicoverpa armigera. J Econ Entomol 98:568-576

Sharma HC, Dhillon MK, Arora R (2008) Effects of Bacillus thuringiensis $\delta$ endotoxin fed Helicoverpa armigera on the survival and development of the parasitoid Campoletis chlorideae. Entomol Exp Applic 126:1-8

Sharma HC, Sujana G, Manohar Rao D (2009) Morphological and chemical components of resistance to pod borer, Helicoverpa armigera in wild relatives of pigeonpea. Arth PI Interact 3:151-161

Sharma HC, Srivastava CP, Durairaj C, Gowda CLL (2010) Pest management in grain legumes and climate change. In: Yadav SS, McNeil DL, Redden R, Patil SA (eds) Climate change and management of cool season grain legume crops. Springer Science + Business Media, Dordrecht, The Netherlands, pp $115-140$

Sirot E, Bernstein C (1996) Time searching between host searching and food searching in parasitoids: state-dependent optimal strategies. Behav Ecol 7:189-194

Sithanantham S, Rao VR, Reed W (1982) The influence of host-plant resistance in chickpea on parasitism of $\mathrm{H}$. armigera Hubner larvae. Inter Chickpea Newslett 6:21-22

Sujana G, Sharma HC, Manohar Rao D (2008) Antixenosis and antibiosis components of resistance to pod borer, Helicoverpa armigera in wild relatives of pigeonpea. Int J Trop Insect Sci 28:191-200

Tian SP, Zhang JH, Yun-Hua Yan YH, Wang CZ (2008) Interspecific competition between the ichneumonid Campoletis chlorideae and the braconid Microplitis mediator in their host Helicoverpa armigera. Entomol Exp Applic 127(10-19):2008

Tumlinson JH, Turlings TCJ, Lewis WJ (1993) Semiochemically mediated foraging behavior in beneficial parasitic insects. Arch Insect Biochem Physiol 22:385-391

Turlings TCJ, Tumlinson JH (1992) Systemic release of chemical signals by herbivore injured corn. Proc Natl Acad Sci U S A 89:8399-8402

Turlings TCJ, Scheepmakeer JWA, Vet LEM, Tumlinson JH, Lewis WJ (1990) How contact foraging experiences affect preferences of host related odours in the larval parasitoid, Cotesia merginiventris Cresson (Hymenoptera: Braconidae) J Chem Ecol 16:1577-1589

Turlings TCJ, Loughrin JH, McCall PJ, Rse USR, Lewis WJ, Tumlinson JH (1995) How caterpillar damaged plants protect themselves by attracting parasitic wasps. Proc Natl Acad Sci U S A 92:4169-4174

Udayagiri S, Jones RL (1992) Flight behavior of Macrocentrus grandii Goidanich (Hymenoptera, Braconidae), a specialist parasitoid of European corn borer (Lepidoptera, Pyralidae)-factors influencing response to corn volatiles. Environ Entomol 21:1448-1456

Vet LEM, Groenewold AW (1990) Semiochemicals and learning in parasitoids. J Chem Ecol 16:3119-3135

War AR, Sharma HC, Paulraj MG, War MY, Ignacimuthu S (2011) Herbivore induced plant volatiles - their role in plant defense for pest management. PI Sig Behav 6(12):1973-1978
Whitaman TG, Maschinski J, Larson KC, Paige KN (1991) Plant response to herbivory: the continuum from negative to positive and underlying physiological mechanisms'. In: Price PW, Lewsinsohn TM, Fernandes GW, Benson WW (eds) Plant animal interactions evolutionary ecology in tropical and temperate regions. Wiley and Sons, New York, pp 227-256

Whitman DW (1988) Allelochemical interactions among plants, herbivores and their predators. In: Barbosa P, Letourneau DK (eds) Novel aspects of insect-plant interactions. Wiley, New York, pp 11-64

doi:10.1186/2193-1801-3-378

Cite this article as: Hugar et al:: Pigeonpea genotypes influence parasitization preference and survival and development of the Helicoverpa armigera larval parasitoid, Campoletis chlorideae. SpringerPlus 2014 3:378.

\section{Submit your manuscript to a SpringerOpen ${ }^{\odot}$ journal and benefit from:}

- Convenient online submission

- Rigorous peer review

- Immediate publication on acceptance

- Open access: articles freely available online

- High visibility within the field

- Retaining the copyright to your article

Submit your next manuscript at $>$ springeropen.com 